\title{
Efficiency Upgrade in PWRs
}

\author{
Morteza Gharib ${ }^{1}$, Abdolazim Yaghooti ${ }^{1}$, Majid Oloomi Buygi ${ }^{2}$ \\ ${ }^{1}$ Amirkabir University of Technology, Tehran, Iran \\ ${ }^{2}$ Ferdowsi University of Mashhad, Mashhad, Iran \\ E-mail: \{mgharib,ayaghooti\}@aut.ac.ir \\ Received April 25, 2011; revised May 28, 2011; accepted June 13, 2011
}

\begin{abstract}
Most of the light water reactor power plants now operating or under construction use pressurized-water reactor (PWR). They are suffering of relatively low thermal efficiency which is around 33\%. This would not only have a negative impact economically but also incurs environmental burden in terms of thermal pollution. In this paper, nuclear steam supply system of a typical PWR has been taken into consideration using 1000 $\mathrm{MW}_{e}$ Bushehr nuclear power plant (BNPP) data. It is shown thermal efficiency could conceivably be increased by superheating live steam with natural gas up to around $40 \%$, competing with similar fossil-fueled power plants. It is further shown that fuel cost (natural gas) as low as $0.12 \mathrm{Cent} / \mathrm{MW}_{e}$, extra power generated is feasible.
\end{abstract}

Keywords: Upgrade Efficiency, Nuclear Power Plant, PWR

\section{Introduction}

Basic human needs can be met only through industrial growth, which depends to a great extent on energy supply. The large increase in population during the last few decades and the spurt in industrial growth have placed tremendous burden on the electrical utility industry and process plants producing chemicals, petrochemicals, and other essential commodities, resulting in the need for additional capacity in the areas of power and steam generation throughout the world. Steam is used in nearly every industry, and it is well known that steam generators and heat recovery boilers are vital to power and process plants. It is no wonder that with rising fuel and energy costs engineers in these fields are working on innovative methods to generate electricity, improve energy utilization in these plants, recover energy efficiently from various waste gas sources, and simultaneously minimize the impact these processes have on environmental pollution and the emission of harmful gases to the atmosphere.

It is a common practice in fossil-fueled power plants to boost live steam entering turbine by superheating it. This would not only increase its thermal efficiency but also this reduces the problem of blade erosion and increases the turbine efficiency in actual cycles. Moreover, this means that less heat would be injected to an already thermally polluted environment $[1,2]$. Nuclear power plants (NPP), in contrast with fossil-fueled power plant, contribute their power to the working fluid through a solid substance known as nuclear fuel. This obviously prevents approach to high temperatures and thus high thermal efficiencies. Therefore approaching to a higher thermal efficiency for NPPs is very attractive. There are several approaches to accomplish this. One approach to achieve high temperatures, using gas cooled reactors which employing ceramic, but still solid, nuclear fuels such as dispersed UC fuels within graphite bed [3]. Therefore high operating temperatures is possible thanks to ceramic and graphite high melting points. Currently, light water reactors (LWR) are the most common type of operational reactors in nuclear industry worldwide, among them pressurized water reactors (PWR) are most prominent [3]. Thus, for the time being, the easiest approach is to improve existing reactors. Since fuel and other structural materials in these reactors are pushed at their extreme working conditions, therefore attention may only be restricted to the working fluid in PWRs. A chronic problem with PWRs, as well as with boiling water reactors (BWR), is that steam production is in saturated state. Thus, the very first step on improving thermo dynamical cycle of such reactors is to boost live steam into a superheating state. This could be achieved by using any form of external heat source economically available, including natural gas [4]. In the following, BNPP is taken as a generic $1000 \mathrm{MW}_{e} \mathrm{NPP}$ and its gen- 
eral data is adopted as a preliminary model. The underlining approach is to include an extra module at the steam generator outlet to increase steam enthalpy and thus producing superheat steam with the aid of natural gas. It is shown that there is a good outlook for this method especially where natural gas is cheap and abundant.

\section{Modeling}

\subsection{Basic Model}

In order to work out a simple model for which comparison could easily be established, a simplified diagram of a generic PWR is taken as the basis of calculations. For the purpose of application, technical data of BNPP is applied. In PWRs, modification is only applied to the secondary loop where live steam is produced in steam generator. The same approach could also be applied to BWRs but on the primary loop where saturated steam exits from reactor itself. In no case, nuclear section is to be interfered. Figure 1 shows the schematic diagram of secondary loop of BNPP. In order to facilitate calculations, 4-staged turbines are reduced into two turbines; one high pressure, and one low pressure. Furthermore, condenser is simplified with working temperature at $70^{\circ} \mathrm{C}$. In this way thermal efficiency of the plant is maintained at the same level as 34\%.

Table 1 shows thermo dynamical data for each point on this diagram. This diagram is considered as a reference diagram for later improvements. The most important parameters needed for this analysis are, temperature, $\mathrm{T}$, pressure, $\mathrm{P}$, and enthalpy, h. It should be noted that in regular NPPs, steam leaves steam generator in saturated state while in this approach, it is intended that heat to be added via an external heat source which is indicated in Figure 1 by "heater". As indicated in this figure, all conditions at point 8 are to be equivalent with BNPP working conditions. Heater is the only module added at this point on steam generator exit for superheating at constant pressure.

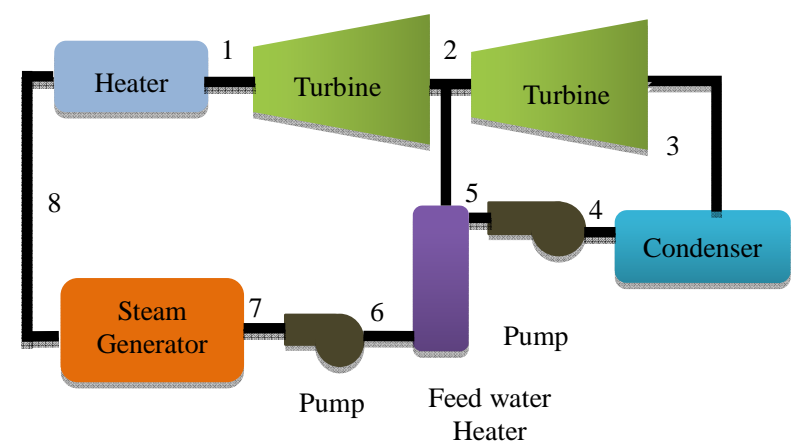

Figure 1. Simplified diagram of secondary loop of BNPP with additional heater.
Table 1. Thermo dynamical parameters of BNPP at its nominal working condition for reference diagram.

\begin{tabular}{|c|c|c|c|c|}
\hline Point & $\mathrm{T}\left({ }^{\circ} \mathrm{C}\right)$ & P (bar) & h (kj/kg) & $\mathrm{S}(\mathrm{kj} / \mathrm{kg} \cdot \mathrm{k})$ \\
\hline 1 & 275.6 & 60 & 2791 & 5.897 \\
\hline 2 & 160.2 & 6.212 & 2391 & 5.901 \\
\hline 3 & 70 & 0.311 & 1990 & 5.901 \\
\hline 4 & 70 & 0.311 & 292.8 & 0.953 \\
\hline 5 & 70 & 6.212 & 293.4 & 0.953 \\
\hline 6 & 160.2 & 6.212 & 676.1 & 1.944 \\
\hline 7 & 160.2 & 60 & 682.1 & 1.944 \\
\hline 8 & 275.6 & 60 & 2791 & 5.897 \\
\hline
\end{tabular}

At point 1 , superheat steam enters into turbine and its enthalpy converts into work in an isentropic manner. At point 2, steam is partially used for feed water preheating and the rest enters into second turbine to do the same thing as in the first one. Low energy vapor enters into condenser at point 3 to make condensate water at constant pressure. Note that temperature is also stay constant in this process. Finally, water is pressurized and pumped through feed water heater rushing into steam generator as usual.

\subsection{Assumptions}

In order to determine the role of external heater and find out about its importance, one has to fix the conditions on some key points on reference diagram. At point 8 (steam generator exit) it is assumed that all data are remained unchanged with respect to original design (having saturated enthalpy at $2791 \mathrm{kj} / \mathrm{kg}$ and mass flow rate fixed at $1661 \mathrm{~kg} / \mathrm{s}$ ). At points 3 and 4, condenser working temperature is forced to be at the same level of $70^{\circ} \mathrm{C}$ for all options. To make the modeling further simple, enthalpy at point 2 is imposed as the average value between point 1 and 3. In this model, it is implicitly assumed that our external heater works with efficiency close to $100 \%$ and there are no other heat losses from this unit. In other words heat of combustion of natural gas is totally absorbed by working steam. Note that the unit indicated by heater in this diagram could exploit any kind of heat source in principle. Considering ease of use and its abundance, natural gas could be the best alternative for this purpose.

\section{Calculation}

Starting with conditions similar to BNPP, heat is added step by step at point 8 and observation is made as to what 
happens to thermal efficiency of the whole plant. It is assumed that a natural gas burner is employed for heat addition to saturated steam at steam generator's exit. For each step, enthalpy is increased by 100 units. Table 2 shows a brief result on new improved efficiencies. As observed, efficiency would raise from nominal 34\% in standard design to improved values up to $38.5 \%$ in proposed model.

In order to conform to conditions prevailed on combined cycle turbine system, resulting superheat steam temperature confined not to exceed $576^{\circ} \mathrm{C}$. This is to prevent all risks witch could endanger turbine blades due to extreme conditions. To achieve this temperature, we consider that gas combustion is done at pressure and temperature $100 \mathrm{kpa}, 25^{\circ} \mathrm{C}$ respectively, and requirement power to achieve from $275^{\circ} \mathrm{C}$ to $538^{\circ} \mathrm{C}$ is $620146.44 \mathrm{kj} / \mathrm{s}$ $(=\mathrm{kw})$, natural gas fuel mass flow rate and air mass flow rate for combustion are $38.72 \mathrm{~kg} / \mathrm{s}, 1335 \mathrm{~kg} / \mathrm{s}$ respectively, factor proportion of air to natural gas fuel is 34.47 $\mathrm{kg}$ (Air)/kg(Fuel). As assistance for calculations, engineering equation solver (EES) is used [5].

At each step, enthalpy at point 1 on reference diagram is increased by 100 units and other physical properties at other key points are calculated with EES taking into account that aforementioned assumptions are observed.

\section{Discussions}

Referring to Table 2, it is quite obvious that hybrid NPP system could deliver high efficiencies up to around 39\%. This model applies 2-staged turbine for the sake of simplicity while in reality, even higher efficiencies around $40 \%$ are achievable since 4 -staged turbine is more efficient. With these high efficiencies, thermal pollution is lessened and up to $30 \%$ less waste heat would be transferred to natural environment.

Table 3 shows economic savings one might get if natural gas superheat is employed in a typical $1000 \mathrm{MW}_{e}$

Table 2. Efficiency improvement as a result of superheating steam in BNPP.

\begin{tabular}{ccccc}
\hline step & Steam condition upon exit of heater & $\begin{array}{c}\text { Entrance enthalpy to turbine } \\
\mathbf{h}(\mathbf{k j} / \mathbf{k g})\end{array}$ & $\begin{array}{c}\text { Entrance steam temperature at turbine } \\
\mathbf{T}\left(\mathbf{}^{\circ} \mathbf{C}\right)\end{array}$ & $\begin{array}{c}\text { Efficiency } \\
\boldsymbol{\eta}(\mathbf{\%})\end{array}$ \\
\hline 1 & saturated steam & 2791 & 275.6 & 34.2 \\
2 & super heat steam & 2900 & 304.5 & 34.73 \\
3 & super heat steam & 3000 & 334.9 & 35.04 \\
4 & super heat steam & 3100 & 370 & 35.45 \\
5 & super heat steam & 3200 & 408.4 & 35.96 \\
6 & super heat steam & 3300 & 449 & 36.54 \\
7 & super heat steam & 3400 & 490.9 & 37.17 \\
9 & super heat steam & 3500 & 533.6 & 37.82 \\
\hline
\end{tabular}

Table 3. Cost-benefit analysis of a generic NPP using natural gas as external heat source Two scenarios: gas price $=2$ Cent $/ \mathrm{m}^{3}$ and gas price $=26 \mathrm{Cent} / \mathrm{m}^{3}$.

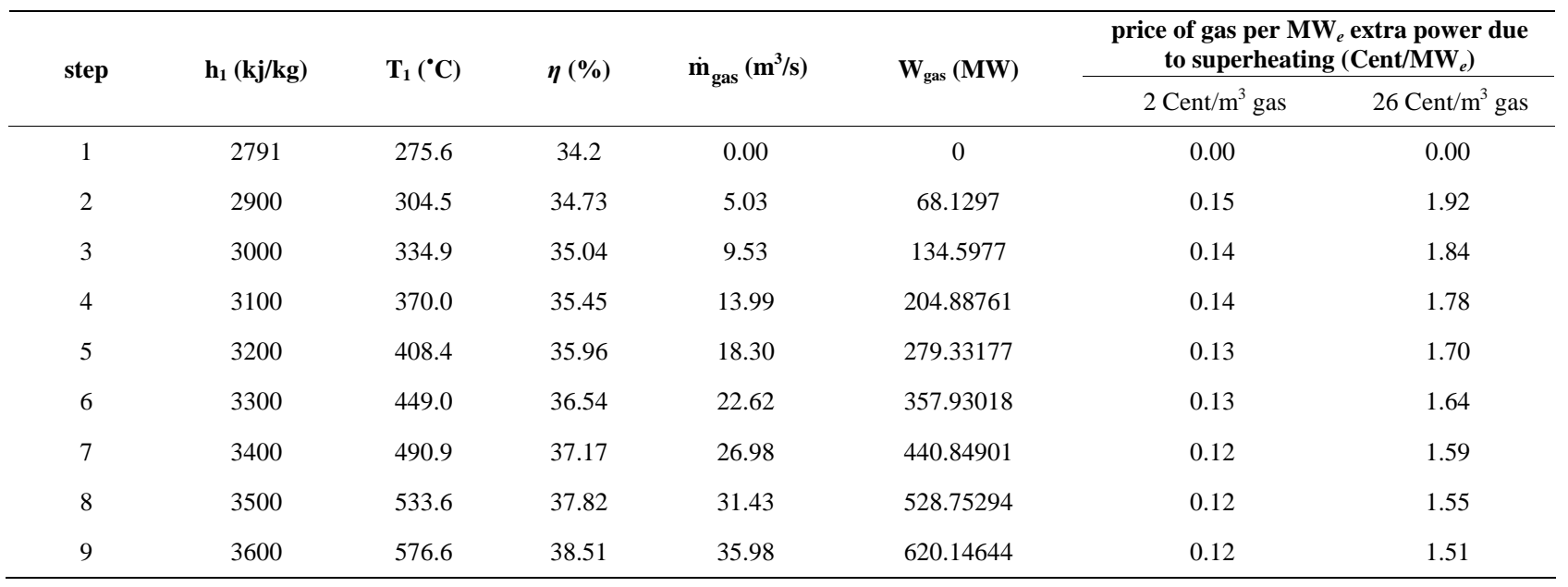


NPP (data are given for BNPP). As a result of enthalpy boost to saturated steam, net extra power is calculated and tabulated. In the cost column, price of gas consumed per extra $\mathrm{MW}_{e}$ power produced as a result of superheating is computed and tabulated. In this table, $\mathrm{W}_{\text {gas }}$ is requirement power that should be generated from gas combustion, $\eta$ is the efficiency, $h_{1}$ is the enthalpy in point $1, \mathrm{~T}_{1}$ is the temperature in point 1 and $\dot{\mathrm{m}}_{\mathrm{gas}}$ is flow rate of gas at $\mathrm{m}^{3} / \mathrm{s}$.

Two scenarios are used in this report. One scenario for Iran and other countries with low price tag as $2 \mathrm{Cent} / \mathrm{m}^{3}$ [6]. Second scenario for OECD countries with price tag as high as $26 \mathrm{Cent} / \mathrm{m}^{3}$ [7]. In this analysis heat content of natural gas is taken as $34680 \mathrm{kj} / \mathrm{m}^{3}$. It is interesting to note that as the degree of superheating is increased, total plant efficiency is also increased and, with that, cost of extra power generation is decreased.

\section{Conclusions}

Parameters of BNPP are adopted as a generic $1000 \mathrm{MW}_{e}$ nuclear power plant. It is shown that, as far as fuel is concerned, extra power produced by natural gas is very cheap. For gas producing countries, such as Iran and GCC countries, where gas is cheap, and for a case that plant efficiency is increased close to $40 \%$ price of gas per $\mathrm{MW}_{e}$ excess power is around 0.12 Cent. This figure, for the same conditions except for OECD countries with gas price around $26 \mathrm{Cent} / \mathrm{m}^{3}$ is about 1.5 Cents. Although capital investment for burner has not been taken into account, but it is conceived that even with including its costs, it is still economical to employ natural gas assisted burner for superheating steam and efficiency increase in nuclear power plants. This, again, emphasizes on the fact that maintaining higher efficiencies results to direct low power generation cost.

\section{References}

[1] L. S. Tong and J. Weisman, "Thermal Analysis of Pressurized Water Reactor,” 3rd Edition, American Nuclear Society Book Publishing, New York, 1996

[2] E. Jeffs, "Generating Power at High Efficiency: Combined-Cycles Technology for Sustainable Energy Production,” Woodhead Publishing Limited, Cambridge, 2008.

[3] A. V. Nero Jr., “A Guidebook to Nuclear Reactors,” University of California Press, Ewing, 1979.

[4] M. Gharib, "Natural Gas Superheat Steam in PWRs," The 4th International Conference of Safety Assurance of Nuclear Power Plants with WWER, Podolsk, 23-26 May 2005.

[5] K. Kwangil, Engineering Equation Solver (EES), version 4.789, Samsung Electronics Co., Korea, 1992-1998.

[6] National Iranian Oil Company Site. http://www.nc.org.ir

[7] International Energy Agency, Organisation for Economic Co-operation and Development "Projected Cost of Generating Electricity,” OECD Publishing, Paris, 2005. 